\title{
YOĞUN BAKIM HEMŞİRELERİNDE NÖBET SONRASI GÖZYAŞI BULGULARININ DEĞERLENDİRILMESİ
}

\author{
Assessment of Tear Film Parameters after Working Overnight in Intensive Care Nurses
}

\author{
Ali Hakim REYHAN', Burak BİLGÍN²
}

\author{
${ }^{1}$ Kilis Devlet Hastanesi, Göz Hastalıkları Kliniği, KİLIS, TÜRKIYYE \\ ${ }^{2}$ Bahçeşehir Üniversitesi Tıp Fakültesi, Göz Hastalıkları A.D., Medicalpark Hastanesi, GAZIAANTEP, TÜRKIYYE
}

\begin{abstract}
ÖZ
Amaç: Yoğun bakım servisleri 24 saat yoğun mesainin yapıldığı, personelin yeterli özen ve dikkatini gerektiren özel yalıtılmış alanlardır. Bu birimlerde mesai yapan personel büyük bir özveri ile yoğun bir tempoda çalışmaktadır. Bu çalışmada, yoğun bakım hemşirelerinde nöbet sonrası durumun gözyaşı testleri üzerine etkisi araştırıld.
\end{abstract}

Gereç ve Yöntem: Oküler ve sistemik hastalığı olmayan 32 gönüllü sağlık personelinin 64 gözü çalışma kapsamına alındı. Çalışmaya katılan gönüllülerin tam oftalmolojik muayenesi yapıld1. Yoğun bakım hemşireleri nöbete başlamadan önce saat 16:00'da olmak üzere ve nöbet sonrası saat $08: 30$ 'da olmak üzere Schirmer 1 testi ve gözyaşı kırılma zamanı testi ile değerlendirildi.

Bulgular: Katılımcıların biyomikroskopik ve fundus muayenesi normal olarak değerlendirildi. Çalışmamızda ortalama göz içi basınc sağ gözde $14.21 \mathrm{mmHg}$, sol gözde $13.75 \mathrm{mmHg}$ olarak bulundu. Nöbet öncesi bakılan Schirmer 1 testi; sağ gözde ortalama $26.28 \mathrm{~mm}$, sol gözde ortalama $24.21 \mathrm{~mm}$ olarak bulunurken, nöbet sonrası Schirmer 1 testi sağ gözde ortalama $19.53 \mathrm{~mm}$, sol gözde ortalama $17.71 \mathrm{~mm}$ olarak bulundu. Schirmer 1 testi her iki göz için nöbet öncesi ve nöbet sonras1 karşılaştırıldığında istatistiksel olarak anlamlı fark bulundu $(\mathrm{p}=0.00)$. Gözyaşı kırılma zamanı testi ise nöbet öncesi sağ gözde ortalama 16.78 sn, sol gözde ortalama 14.43 sn, nöbet sonrası sağ gözde ortalama $9.08 \mathrm{sn}$, sol gözde ortalama 8.71 sn olarak tespit edildi. Gözyaşı kırılma zamanı testi her iki göz nöbet öncesi ve nöbet sonrası değerler karşılaştırıldığında istatistiksel olarak anlamlı fark bulundu $(\mathrm{p}=0.00)$.

Sonuç: Yoğun bakım hemşilerinde, nöbet sırasında uykusuz kalmanın gözyaşı kırılma zamanı ve Schirmer testi değerlerinde olumsuz değişiklikler yaptığı görülmüştür.

Anahtar Kelimeler: Yoğun bakım hemşireleri, Schirmer testi, Gözyaşı kırılma zamanı

\section{ABSTRACT}

Objective: Intensive care unit is a special area with many lifesaving technological tools and equipment. It is isolated with its general appearance and atmosphere. In these units, intensive care nurses with special skills work at a fast and intensive pace for special purposes. In this study, the effect of working shifts on tear tests of intensive care nurses was investigated.

Material and Method: Thirty-two health workers without ocular or systemic disease who volunteered were included in the study. Complete ophthalmologic examination of sixty-four eyes was performed. The intensive care nurses were evaluated with Schirmer 1 test and Tear break up time test before the working shift at 16:00 and after the working shift at 08:30.

Results: The group's biomicroscopic examination and fundus examination were evaluated as normal before the study. The average intraocular pressure was $14.21 \mathrm{mmHg}$ in the right eye and $13.75 \mathrm{mmHg}$ in the left eye. Schirmer 1 test was done before working shift. The average was $26.28 \mathrm{~mm}$ in the right eye and $24.21 \mathrm{~mm}$ in the left eye. While the average Schirmer 1 testing after working shift was $19.53 \mathrm{~mm}$ in the right eye, the average was $17.71 \mathrm{~mm}$ in the left eye. Schirmer 1 test was found as statistically significant in both eyes before and after the working shift $(\mathrm{p}=0.00)$. Tear break up time test was found to be 16.78 seconds in average in right eye and 14.43 seconds in the left eye before the working shift. On the other hand, the test time was averagely 9.08 seconds in right eye and 8.71 seconds in the left eye after the working shift. Significant difference was found in tear break up time test when tear break up times before and after shifts were compared $(\mathrm{p}=0.00)$.

Conclusion: Tear break up time test and Schirmer test values are decreasing after the working shift due to the lack of sleep of intensive care nurses.

Keywords: Intensive care nurses, Schirmer test, Tear break up time

\footnotetext{
* Bu çalışma, 5-7 Nisan 2018 tarihinde Gaziantep’te düzenlenen 3. Dahili ve Cerrahi Yoğun Bakım Hemşireliği Kongresi'nde sözlü bildiri olarak sunulmuştur.
} 


\section{GíRiș}

Yoğun bakım servisi, hastanelerin çok sayıda yaşam kurtarıcı teknolojik araç ve gereçlerinin bulunduğu, genel görünümü ve atmosferi ile yalıtılmış özel alanlarıdır. Bu birimlerde becerisi ve özel amacı olan yoğun bakım hemşireleri, hızlı ve yoğun bir tempoda çalışmaktadır. Birçok yoğun bakım hemşiresi, ekonomik ya da sosyal şartlar nedeniyle gece saatlerini de içeren vardiyalar halinde çalışmaktadırlar. Haftada 40 saaten fazla olmak üzere 12 saat, 16 saat ya da 24 saatlik vardiyalar halinde çalışmayı tercih etmektedirler. Çalışanın içinde bulunduğu çalışma ortamının fiziksel koşullarının, iş yükünün fazlalığının ve uzun çalışma saatlerinin neden olduğu stresin kronik hastalıkların gelişmesine zemin hazırladığı bilinmektedir (1). Yoğun bakım hemşirelerinin işlerinde yaşadıkları fiziksel ve duygusal stres, aile içinde ve sosyal yaşamda üstlendikleri sorumlulukları ve dinlenme sürelerinin yetersiz olması, uyku bozukluğu ile birlikte stres seviyelerinin yükselmesine neden olmaktadir $(2,3)$.

Kuru göz hastalığı; gözyaşının eksikliği veya aşırı buharlaşması sonucu görülen oküler yüzey enflamasyonu olarak tanımlanabilir (4). Hastalarda yaygın olarak oküler yüzey konforsuzluğuna neden olan batma, yanma, basınç hissi, yabancı cisim hissi ve görme bozuklukları belli başlı şikayetlerdir $(5,6) . \mathrm{Bu}$ hastalar, kuru göz hastalığının ciddiyetine göre yaşam kalitesinin azalmasından muzdarip olabilmektedirler (7). Gözyaşı salgısının düzenlenmesi sinirsel ve hormonal kontrol altındadır (8). Kuru göz hastalığı; depresif bozukluklar, ilaç kullanımı, hormonal dalgalanmalar ve sistemik hastalıklar gibi birçok durum ile yakından ilgilidir (6).

Daha önce yapılmış birçok çalışmalarda mental sağlık durumu ile kuru göz arasında bağlantı olduğu belirtilmiştir. $\mathrm{Bu}$ çalışmalarda özellikle; kuru göz semptomlarının, anksiyete ve stres ile yakın ilişkili olduğu görülmüştür (9-11). Kore nüfusu tabanlı bir çalışmada hafif ya da orta derecede uyku bozukluğu olanların kontrol grubu ile karşılaştırıldıklarında kuru göz riskinde artış olduğu bulunmuştur (12). Öğrencilerde yapılan bir çalışmada ise düşük uyku kalitesinin kuru göz hastalığı ile ilişili olduğu belirtilmiştir (13). Ofis çalışanlarında yapılan diğer bir çalışmada ise uyku kalitesindeki azalma ile Schirmer değerlerinde azalma arasında ilişki olduğu belirtilmiştir (14). Uyku bozukluğu, otonomik ve endokrin fonksiyonlar ile yakın ilişkili olduğu bilinmektedir $(15,16)$. Aynı zamanda uyku yoksunluğunun kan basıncını ve stres hormon düzeylerini artırdığı ve parasempatik aktiviteyi azalttığı gösterilmiştir $(17,18)$.

Yoğun bakım hemşirelerinin gece nöbetlerinde uykusuz kalması, 1şık ve stres maruziyetine bağlı olarak sirkadiyen ritmlerini etkileyebilmektedir. Bu çalışmada; yoğun bakım hemşirelerinin tutmuş oldukları nöbetin gözyaşı parametreleri üzerindeki etkisini değerlendirmeyi amaçladık.

\section{GEREÇ VE YÖNTEM}

Kilis devlet hastanesi yoğun bakım ünitesinde Kasım 2017- Ocak 2018 tarihleri arasında 32 gönüllü sağlık personelinin 64 gözü çalışmaya dahil edildi. Tüm araştırma Helsinki Deklarasyonu kurallarına uygun şekilde ve hastaların bilgilendirilmiş onam formları alınarak yürütüldü. Çalışmanın yürütülmesi için Sanko Üniversitesi Tıp Fakültesinden yerel etik kurul onayı alındı. (Tarih: 29.09.2017, karar no: 06/2017). Sistemik hastalık öyküsü, kuru göz bulgusu, göz cerrahisi öyküsü, bilinen göz hastalığı, geçirilmiş göz travması olanlar, göz damlası kullanan ve kontak lens kullanan bireyler çalışma dışı bırakıldı. Hastaların tümüne çalışma öncesi "En iyi düzeltilmiş görme keskinliği”" (EIDGK), biyomikroskopik muayene ve non-kontakt tonometre ile göz içi basınç ölçümünü içeren genel oftalmolojik muayene yapıldı.

Tüm gönüllüler nöbete başlamadan önce saat 16:00'da ve nöbet sonrası saat $08: 30$ 'da olmak üzere toplam iki kez Schirmer 1 testi ve gözyaşı kırılma zamanı (GKZ) testi ile değerlendirildi. Schirmer 1 testi; topikal anestezi uygulanmadan Schirmer kağıdı bir uçtan 5 
mm kıvrılarak (Erc schirmer tear test strip, Erc sağlık, Ankara, Türkiye) alt göz kapağının orta ve üçte bir lateral kısmının kesişimine yerleştirildi. Schirmer kağıdı yerleştirildikten sonra hastadan karşıya bakması ve normal şekilde göz kırpması istendi. Schirmer kağıdı beş dakika sonra alınarak ölçüm kaydedildi. GKZ, floresein uygulanmasından sonra hastanın üç kez gözünü kırpması ve daha sonra gözlerini açık tutarak bakması istenerek ölçüldü. Kobalt mavisi altında korneadaki kuru noktanın oluşma süresi değerlendirilerek kaydedildi. Testler arasında 10 dakika beklendi.

\section{Istatistiksel Analiz}

Elde edilen veriler SPSS 16.0 (Statistical Packagefor the Social Sciences, IBM) ortamında bilgisayara kaydedildi. Karşılaştırmalarda wilcoxon testi kullanıldı. Değerlendirmeler \%95 güven aralığında yapıldı. p değerinin 0.05 'ten küçük olması istatistiksel olarak anlamlı olarak kabul edildi.

\section{BULGULAR}

Çalışmaya katılan 32 sağlık personelinin 64 gözü değerlendirildi. Grubun 18'i kadın (\%56), 14 'ü erkek (\%44) idi. Grubun yaşları 20 yıl ile 33 yıl arasında değişmekte olup, ortalama yaşı $24.12 \pm 2.87$ yıl idi. Grubun en iyi düzeltilmiş görme keskinliği Snellen eşeline göre her iki göz tam olarak bulundu. Çalışmamızda göz içi basınc sağ gözde ortalama 14.21 $\mathrm{mmHg}$ sol gözde ortalama $13.75 \mathrm{mmHg}$ olarak bulundu (Tablo 1).

Grubun biyomikroskopik ve fundus muayenesi normal olarak değerlendirildi. Nöbet öncesi bakılan Schirmer testi; sağ gözde ortalama $26.28 \mathrm{~mm}$, sol gözde ortalama $24.21 \mathrm{~mm}$ olarak bulunurken, nöbet sonrası Schirmer testi sağ gözde ortalama $19.53 \mathrm{~mm}$, sol gözde ortalama $17.71 \mathrm{~mm}$ olarak bulundu. Schirmer testi her iki göz için nöbet öncesi ve nöbet sonrası karşılaştırıldığında istatistiksel olarak anlaml fark bulundu $(\mathrm{p}=0.00)$ (Tablo 2).

GKZ ise nöbet öncesi sağ gözde ortalama 16.78 sn, sol gözde ortalama 14.43 sn, nöbet sonrası sağ gözde ortalama $9.08 \mathrm{sn}$, sol gözde ortalama 8.71 sn olarak tespit edildi. GKZ her iki göz nöbet öncesi ve nöbet sonrası değerler karşılaştırıldığında istatistiksel olarak anlamlı fark bulundu ( $\mathrm{p}=0.00)$ (Tablo 3 ).

Tablo 1: Çalışmamıza alınan bireylerin demografik özellikleri.

\begin{tabular}{|c|c|c|c|c|}
\hline & En düşük değer & En büyük değer & Ortalama değer & Standart Sapma \\
\hline \multicolumn{5}{|l|}{ Yaş } \\
\hline Erkek (y1l) & 20 & 33 & 25.14 & 3.25 \\
\hline Kadın (y1l) & 20 & 29 & 23.33 & 2.37 \\
\hline \multirow[t]{2}{*}{ Cinsiyet } & Erkek & Kadın & & \\
\hline & $14(\% 44)$ & $18(\% 56)$ & & \\
\hline \multirow[t]{2}{*}{ GİB (mmHg) } & Sağ göz & Sol göz & & \\
\hline & 14,21 & 13,75 & & \\
\hline EİDGK(Snellen) & 1 & 1 & & \\
\hline
\end{tabular}


Tablo 2: Schirmer testinin her iki gözde nöbet öncesi ve nöbet sonrası karşılaştırılması.

\begin{tabular}{|c|c|c|c|c|c|}
\hline & $\begin{array}{c}\text { En düşük } \\
\text { değer }\end{array}$ & $\begin{array}{c}\text { En büyük } \\
\text { değer }\end{array}$ & $\begin{array}{c}\text { Ortalama } \\
\text { değer }\end{array}$ & $\begin{array}{c}\text { Standard } \\
\text { Sapma }\end{array}$ & P değeri \\
\hline \multicolumn{6}{|c|}{ Nöbet öncesi Schirmer testi } \\
\hline Sağ göz (mm) & 15 & 35 & 26.28 & 7.80 & 0,00 \\
\hline Sol göz (mm) & 10 & 35 & 24.31 & 8.02 & 0,00 \\
\hline \multicolumn{6}{|c|}{ Nöbet sonrası Schirmer testi } \\
\hline Sağ göz (mm) & 5 & 35 & 19.53 & 10.85 & \\
\hline Sol göz (mm) & 5 & 35 & 17.71 & 10.73 & \\
\hline
\end{tabular}

Tablo 3: GKZ (Gözyaşı kırılma zamanı) testinin her iki gözde nöbet öncesi ve nöbet sonrası karşılaştırılması.

\begin{tabular}{|c|c|c|c|c|c|}
\hline & $\begin{array}{c}\text { En düşük } \\
\text { değer }\end{array}$ & $\begin{array}{c}\text { En büyük } \\
\text { değer }\end{array}$ & $\begin{array}{c}\text { Ortalama } \\
\text { değer }\end{array}$ & $\begin{array}{c}\text { Standard } \\
\text { Sapma }\end{array}$ & P değeri \\
\hline \multicolumn{6}{|c|}{ Nöbet öncesi GKZ testi } \\
\hline Sağ göz (sn) & 9 & 35 & 16.78 & 7.84 & 0,00 \\
\hline Sol göz (sn) & 8 & 25 & 14.43 & 4.25 & 0,00 \\
\hline \multicolumn{6}{|c|}{ Nöbet sonrası GKZ test } \\
\hline Sağ göz (sn) & 4 & 24 & 9.06 & 4.64 & \\
\hline Sol göz (sn) & 3 & 20 & 8.71 & 3.88 & \\
\hline
\end{tabular}

\section{TARTIŞMA}

Kuru göz hastalığı gözyaşını ve oküler yüzeyi etkileyen multifaktöriyel bir hastalıktır. Sjögren sendromu, düşük androjen ve yüksek östrojen seviyesi gibi hormonal dalgalanmalar, sistemik ilaçların kullanımı, diyabet hastalığg ve kontakt lens kullanımı kuru göz sendromu için risk faktörleridir (5,19). Ayrıca, kuru göz sendromunun post travmatik stres bozukluğu ve depresyon ile ilişkili olabileceği bildirilmektedir (9). Uyku yoksunluğuna bağlı hormonal ve nörokimyasal değişiklikler potansiyel olarak komorbiditeye neden olabilecek birçok hastalıkla güçlü bir ilişki içindedir $(15,20)$. Uyku yoksunluğu; hücresel tepkilerin değişmesine, oksidatif strese, stres hormonların seviyelerinin yükselmesine, norepinefrin ve kortizol seviyesinin yükselmesine sebep olur $(15,21)$. Bu çalışmada yoğun bakım hemşirelerinde uzun çalışma saatlerinin neden olduğu uyku yoksunluğu ve stresin gözyaşı stabilitesini bozabileceğini ortaya koyduk. Çalışmamızda 16 saat nöbet sonrası Schirmer ve GKZ testlerinin ortalama değerlerini, nöbet öncesi ölçtüğümüz ortalama değerlere göre daha düşük bulduk.

Uluslarası Kuru Göz Çalışma Grubu (TFOS DEWS 22017) raporuna göre; kuru göz tanı kriterlerinde, GKZ (<10 s), göz yaşı osmolaritesi ölçümü (>308 mOsml/L yada iki göz arasındaki osmolirite farkı $>8 \mathrm{mOsml} / \mathrm{L}$ ), Oküler yüzey boyanması ( $>5$ korneal spotlar, $>9$ konjonktival spotlar, kapak kenarı boyanma $>2 \mathrm{~mm}$ uzunlığu ya da >\%25 genişleme) ve semptomolojik skor anketleri (Ocular Surface Disease Index [OSDI] $\geq$ 13 yada Dry Eye Questionnaire [DEQ-5] $\geq 6$ ) kullanılmaktadır (22). 
GKZ testinin gözyaşının stabilitesini temsil ettiği bilinmektedir (5). Müsin ve diğer faktörlerin neden olduğu yüzey geriliminin değişmesine bağlı GKZ testi de değişecektir (23). Aslında GKZ testinin gözyaşı miktarından çok kaliteyi kontrol ettiği söylenebilir. Bizim çalışmamıza benzer bir çalışma olarak Makateb ve ark.'nın yaptığı çalışmada; gece işcilerinde, iş paydosu sonrası kaydedilen GKZ testininin ortalama değerini, iş başlangıcı öncesi kaydedilen değere göre daha düşük bulmuştur (24). Lee ve ark.'nın yapmış olduğu benzer bir çalışmada uyku yoksunluğunun GKZ ortalama değerini azalttığı bildirilmiştir (25). Makateb'in çalışmasında, gece çalışmanın, gözyaşı filmi dengesizliğine ve göz kuruması semptomlarının şiddetlenmesine neden olabileceği bildirilmiştir (24). Nascimento ve ark. tarafından yapılan bir çalışmada ise uyku bozukluğunun ardından ağrıya duyarlılığın arttığı gösterilmiştir. $\mathrm{Bu}$ bulgu, kuru göz semptomlarının alevlenmesinde de rol oynayabilir (15). Schirmer testleri gözyaşı filminin yapım miktarı hakkında bilgi verirler. Schirmer testi sensitivitelerinin düşük olması nedeniyle kuru göz hastalığı tanı kriterlerinde olmamasına rağmen hala sjögren sendromu tanısınıda kullanılmaktadır (26). Aynı zamanda Schirmer testi, aköz eksikliğine bağlı kuru göz hastalığının tanısal doğruluğunu arttırmak için önerilmektedir (27). Çalışmamızda her iki göz Schirmer testi ortalama nöbet sonrası değeri, nöbet öncesi değerine göre daha düşük bulundu. Lee ve ark.'nın yapmış olduğu çalışmada uyku yoksunluğu olan grupta Schirmer testinin 16. saat ortalama değerleri ilk ölçülen ortalama değerlere göre daha düşük bulunmuştur. Aynı zamanda uykudan yoksun olan grubun Schirmer testi ortalama değerleri kontrol grubuna göre daha düşük bulunmuştur (25). Bizim çalışmamızdan farklı olarak Makateb ve ark., gece işçilerinde, iş paydosu sonrası kaydedilen Schirmer testininin ortalama değerini, iş başlangıcı öncesi kaydedilen değere göre daha yüksek bulmuştur (24). Schirmer testindeki bu değişkenlikler; ortamın sıcaklığı ve nemi, kağıdı yerleştirme şekline, yerleştirilen kağıdın boyutuna kağıdı yerleştirildikten sonra oluşan refleks gözyaşı gibi birçok faktöre bağlıdır (28,29). Gözyaşı bezi sempatik ve parasempatik sinirler tarafindan inerve edilir. Uyku yoksunluğuna bağlı olarak kortizol, epinefrin ve norepinefrin gibi stres hormonlarının düzeylerinin arttırdığı, parasempatik tonusun azaldığı ve sempatik tonusun arttığı bilinmektedir $(15,30,31)$. Gözyaşı bezi üzerinde parasempatik sistem baskındır. Dolaysıyla parasempatik sistem aktive olduğu zaman gözyaşı sekresyonunu uyarır (32). $\mathrm{Bu}$ nedenle uyku yoksunluğu, gözyaşı salgısını potansiyel olarak bozabilir $(11,33)$. Çalışmamıza katılan yoğun bakım hemşireleri genç yaş (ortalama yaş 24.12) grubundan oluşmaktaydı. Kuru göz sendromunun yaşla birlikte arttığı göz önüne alındığında, muhtemelen uyku yoksunluğu ve vücudun normal sirkadiyen ritimlerinin bozulma etkisi yaşlı insanlarda daha olumsuz etkilere sahip olacaktır (24).

Gece çalışmanın neden olduğu uyku yoksunluğunun uzun dönemde etkileri daha fazla olabilir. Kuru göz sendromu, uzun vadede gözyaşı bezlerine zarar veren zamanla gözyaşı filminin niteliğini ve miktarını değiştiren ve oküler yüzey hastalıklarına neden olan enflamatuar bir süreçtir.

$\mathrm{Bu}$ çalışmaya katılan gönüllülerin sayısının az olması, kontrol grubunun olmaması ve oküler yüzey hastalık indeksi gibi (OSDI) semptomolojik skor anketleri kullanılmaması, çalışmanın kısıtlıklıkları arasında sayılabilir. Sonuç olarak yoğun bakım hemşirelerinin nöbet sonrasında uyku yoksunluğuna bağlı olarak GKZ ve Shirmer testi ortalama değerleri azalmaktadır. Bu durum oküler yüzey hastalıklarının gelişmesini tetikleyebilir. $\mathrm{Bu}$ nedenle gece nöbeti tutan yoğun bakım hemşirelerinde kuru göz bulgularının ortaya çıkmaması için özel dikkat gösterilmelidir. Bu durumu önlemeye yönelik nöbet tutan personelin "kurugöz" hakkında bilgilendirilmesi, nöbet sırasında sunni göz yaşı damlalarının kullanılmasının teşvik edilmesi, ortam neminin takip edilmesi ve düzenlenmesi ve personelin çalışma saatlerinin daha makul seviyelere düşürülmesinin faydalı olması beklenebilir. 


\section{KAYNAKLAR}

1. Terzi B, Kaya N. Nursing care of critically ill patients. Yoğun Bakım Dergisi. 2011;1:21-5.

2. Çelik S, Taşdemir N, Kurt A, İlgezdi E, Kubalas Ö. Fatigue in intensive care nurses and related factors. Int J Occup Environ Med. 2017;8(4):1137-99.

3. Books C, Coody L C, Kauffman R, Abraham S. Night Shift Work and Its Health Effects on Nurses. Health Care Manag. 2017;36(4):347-53.

4. Uchino M, Schaumberg DA. Dry eye disease: Impact on quality of life and vision. Curr Ophthalmol. 2013;1(2):51-7.

5. Lemp MA, Bron AJ, Baudouin C, Benítez Del Castillo JM, Geffen D, Tauber $\mathrm{J}$ et al. Tear osmolarity in the diagnosis and management of dry eye disease. Am J Ophthalmol. 2011;151(5):792-8.

6. Johnson ME, Murphy PJ. Changes in the tear film and ocular surface from dry eye syndrome. Prog Retin Eye Res. 2004;23(4):449-74.

7. Ayaki M, Kawashima M, Negishi, K, Kishimoto T, Mimura M, Tsubota K. Sleep and mood disorders in women with dry eye disease. Scientific reports. 2016;6:35276. Doi:10.2147/OPTH.S148650.

8. Kamperis K, Hagstroem S, Radvanska E, Rittig S, Djurhuus JC. Excess diuresis and natriuresis during acute sleep deprivationin healthy adults. Am J Physiol Renal Physiol. 2010; 299(2):404-11.

9. Galor A, Felix ER, Feuer W, Shalabi N, Martin ER, Margolis TP et al. Dry eye symptoms align more closely tonon-ocular conditions than to tear film parameters. Br J Ophthalmol. 2015;99(8):1126-9.

10. Fernandez CA, Galor A, Arheart KL, Musselman DL, Venincasa VD, Florez HJ et al. Dry eye syndrome, post traumatic stress disorder, and depression in an older male veteran population. Invest Ophthalmol Vis Sci. 2013;54(5):3666-72.

11. Wen W, Wu Y, Chen Y, Gong L, Li M, Chen X et al. Dry eye disease in patients with depressive and anxiety disorders in Shanghai. Cornea. 2012;31(6):686-92.
12. Lee W, Lim SS, Won JU, Roh J, Lee JH, Seok H et al. The association between sleep duration and dry eye syndrome among Korean adults. Sleep Med. 2015;16(11):1327-31.

13. Zhang Y, Chen $\mathrm{H}$, Wu X. Prevalence and risk factors associated with dry eye syndrome among senior high school students in acounty of Shandong Province, China. Ophthalmic Epidemiol. 2012;19(4):226-30.

14. Kawashima M, Uchino M, Yokoi N, Uchino Y, Dogru M, Komuro A et al. The association of sleep quality with dry eye disease: the Osaka study. Clin Ophthalmol. 2016;10:1015-21.

15. Nascimento DC, Andersen ML, Hip'olide DC, Nobrega JN, Tufik S. Pain hypersensitivity induced by paradoxical sleep deprivationis not due to altered binding to brain mu-opioid receptors. Behav Brain Research. 2007;178(2):216-20.

16. Everson CA. Functional consequences of sustained sleep deprivation in the rat. Behav Brain Res. 1995;69(1-2):43-54.

17. Leproult R, Copinschi G, Buxton O, Van Cauter E. Sleep loss results in an elevation of cortisol levels the next evening. Sleep. 1997;20(10):865-70.

18. Dartt DA. Neural regulation of lacrimal gland secretoryprocesses: relevance in dry eye diseases. Prog Retin Eye Res. 2009;28(3):155-77.

19. Sullivan DA. Tearful relationships? Sex, hormones andaqueous-deficient dry eye. Ocul Surf. 2004;2(2):92-123.

20. Cirelli C. Cellular consequences of sleep deprivation in the brain. Sleep Med Rev. 2006;10(5):307-21.

21. Ding C, Walcott B, Keyser KT. Sympathetic neural control of the mouse lacrimal gland. Invest Ophthalmol Vis Sci. 2003;44:1513-20.

22. Wolffsohn JS, Arita R, Chalmers R, Djalilian A, Dogru M, Dumbleton $\mathrm{K}$ et al. TFOS DEWS II diagnostic methodology report. Ocular Surf. 2017;15(3):539-74. 
23. Tiffany JM, Pandit JC, Bron AJ. Soluble mucins and the physical properties of tears. Invest Ophthalmol Vis Sci. 1998;438:229-34.

24. Makateb A, Torabifard H. Dry eye signs and symptoms in night-time workers. J Curr Ophthalmol. 2017;29(4):270-3.

25. Lee YB, Koh JW, Hyon JY, Wee WR, Kim JJ, Shin YJ. Sleep deprivation reduces tear secretion and impairs the tear film. Invest Ophthalmol Vis Sci. $2014 ; 55(6): 3525-31$.

26. Vitali C, Bombardieri S, Jonsson R. European Study Group on Classification Criteria for Sjögren's Syndrome. Classification criteria for Sjögren's syndrome: a revised version of the European criteria proposed by the American-European Consensus Group. Ann Rheum Dis. 2002;61(6):554-8.

27. De Monchy I, Gendron G, Miceli C, Pogorzalek N, Mariette X, Labetoulle M. Combination of the Schirmer I and phenol red thread tests as a rescue strategy for diagnosis of ocular dryness associated with Sjögren's syndrome. Invest Ophthalmol Vis Sci. 2011;52(8): 5167-73.

28. Gupta A, Heigle TJ, Pflugfelder SC. Nasolacrimal stimulation of aqueous tear production. Cornea. 1997;16(6):645-8.

29. Chiang B, Asbell PA, Franklin B. Phenol-red thread tear test and Schirmer test for tear production in normal and dry eye patients. Invest Ophthalmol Vis Sci. 1988;29:337.

30. Galor A, Feuer W, Lee DJ, Florez H, Faler AL, Zann KL et al. Depression, post-traumatic stress disorder, dry eye syndrome: a study utilizing the national United States Veterans Affairs administrative database. Am J Ophthalmol. 2012;154(2):340-6.

31. Treuer K, Norman TR, Armstrong SM. Over night human plasma melatonin, cortisol, prolactin, TSH, under conditions of normal sleep, sleep deprivation, and sleep recovery. J Pineal Res. 1996;20(1):7-14.
32.Zoukhri D. Effect of inflammation on lacrimal gland function. Exp Eye Res. 2006;82(5): 885-98.

33. Ding C, Walcott B, Keyser KT. Sympathetic neural control of the mouse lacrimal gland. Invest Ophthalmol Vis Sci. 2003;44(4):1513-20. 